Pediat. Res. 1: 425-435 (1967)

Parathyroid hormone parathyroid gland

vitamin $\mathrm{D}$ deficiency aminoaciduria phosphaturia

hypocalcemia hypophosphatemia rickets

\title{
Hyperparathyroidism as the Cause of Hyperaminoaciduria and Phosphaturia in Human Vitamin D Deficiency
}

\author{
D.Fraser, S.W. KoOH and G.R.SGRIVER ${ }^{[53]}$ \\ DeBelle Laboratory for Biochemical Genetics, The McGill University-Montreal Ghildren's Hospital \\ Research Institute, Montreal, and The Research Institute, Hospital for Sick Children, Toronto, Canada
}

\begin{abstract}
Extract
Thirty-nine infants with simple vitamin D deficiency were studied; three stages of deficiency were recognized. Stage I comprised hypocalcemia, usually as the sole important biochemical finding, while convulsions were a common clinical sign. Stage II revealed normocalcemia with hyperaminoaciduria, hypophosphatemia, and hyperphosphaturia; rickets was also in evidence. Stage III was comparable to stage II, but with recurrence of hypocalcemia and convulsions, the rickets was more severe. Patients progressed spontaneously from the early to the later stages of the deficiency syndrome; administration of parathyroid extract appeared to accelerate the rate of progression. Calcium infusion and vitamin $\mathrm{D}$ therapy each initially raised the serum calcium level in hypocalcemic patients; thereafter, aminoaciduria and hyperphosphaturia were suppressed.

These diverse observations were interpreted in accordance with current knowledge of vitamin D and parathyroid hormone interrelations. The acquired excretory abnormality involving amino acid and phosphorus is the result of impaired tubular absorption; this defect is considered to be dependent on the development of endogenous reactive hyperparathyroidism, and not dependent on cellular deficiency of vitamin $\mathrm{D}$ per se. The stimulus for the hyperparathyroidism is hypocalcemia induced by deficiency of vitamin D. Normocalcemia is restored if sufficient vitamin D is present in cellular membranes to amplify the stimulative action of parathyroid hormone on intestinal transport of calcium and its release from bone. Severe deficiency of vitamin D blocks this regulatory effect upon calcium, but does not block the inhibitory effect of parathyroid hormone on renal tubular transport of amino acids and phosphorus.
\end{abstract}

\section{Speculation}

An excess of parathyroid hormone rather than a simple deficiency of vitamin $\mathrm{D}$ at the renal tubular epithelial cell appears to cause the disturbance of transport affecting the absorption phosphorus, amino acids and other solutes. This impairment of function is the price paid in renal cellular economy for the conservation of calcium. The cellular mechanisms underlying this coexistent inhibitory effect of parathyroid hormone constitutes an important and fascinating subject for further investigation. 


\section{Introduction}

Circumstances still exist in Canada which predispose to vitamin $\mathrm{D}$ deficiency in the human infant. Vitamin $\mathrm{D}$ supplementation of bottled dairy milk is uncommon in this country, and during the winter months infants acquire little vitamin $\mathrm{D}$ from exposure to sunlight. Since fluid milk constitutes the principal nutrient of infants in the poorer urban populations, it is not surprising, therefore, that many cases of vitamin $\mathrm{D}$ deficiency still occur in the spring months among infants born in the previous year.

Vitamin D deficiency can present with a wide variety of manifestations [23]. Among these, the abnormalities of urinary excretion involving phosphorus $[1,23,28]$, amino acids $[19,25,27]$ and bicarbonate $[47,48]$ have long been of interest to investigators. Hyperaminoaciduria has been recognized as a component of the human vitamin $\mathrm{D}$ deficiency syndrome for over 30 years $[6,8,12,19,25,27,45]$; this phenomenon which occurs in some, but not in all infants with vitamin $\mathrm{D}$ deficiency $[8,19,25,45]$ attracted our particular attention. Thirty-nine untreated patients were studied and correlations made of biochemical, clinical and radiographic information. On the basis of the observations to be reported, we propose that the human vitamin $\mathrm{D}$ deficiency syndrome develops progressively in three 'stages' : an early stage with hypocalcemia and minimal bone demineralization; an intermediate stage with normocalcemia, hypophosphatemia, hyperaminoaciduria and moderate rickets; and a later stage with hypophosphatemia, hyperaminoaciduria, reappearance of hypocalcemia and advanced rickets. We suggest these three stages reflect progressive vitamin D depletion, modified by resultant hyperparathyroidism, the latter being the factor which impairs renal tubular function.

\section{Materials and Methods}

\section{Patients}

Thirty-nine infants were investigated. The criteria for acceptance of a patient into the study were:

1. that all investigations were performed at admission on the same day

2. that no therapy (vitamin $D$ or calcium) had been given prior to the investigations

3. that rapid healing of rickets occurred subsequently on a therapeutic dosage of vitamin $D_{2}$ (5000 units/day $\times 4$ weeks) and without recurrence of rickets when the normal daily requirement (400 IU/day) was instituted thereafter.

Determinations of total calcium, inorganic phosphorus and alkaline phosphatase were made on serum or plasma taken in the morning before feeding; the amino acid content of urine was measured, and roentgenograms of skull and long bones were obtained. The $\mathrm{X}$-ray films were evaluated by one radiologist ${ }^{\mathbf{1}}$ without foreknowledge of the patient's biochemical and clinical status.

\section{Analytical Methods}

Calcium was determined by a titrimetric method [9], inorganic phosphorus by the molybdate method [17], and alkaline phosphatase activity by the method of King and Armstrong [30].

Urine samples were obtained by spontaneous voiding and the amino acid content assessed by ascending two-dimensional partition chromatography [13]. An aliquot equivalent to $250 \mu \mathrm{g}$ total nitrogen was chromatographed on 10-inch square Whatman No. 4 filter paper. The chromatogram was first developed in an ammonia atmosphere with water-saturated phenol solvent (Mallinckrodt), which was then dried off overnight at $25^{\circ}$. The second solvent was 2,6-lutidine (95\% Practical-Eastman Organic Chemicals) : water $(2.2: 1)$. After drying overnight, the chromatogram was dipped in a mixture of ninhydrin $(0.25 \% \mathrm{w} / \mathrm{v})$, isatin $(0.01 \%$ $w / v), 2,6$-lutidine $(1 \% \mathrm{v} / \mathrm{v})$, in acetone ${ }^{2}$, and heated at $80^{\circ}$ for ten minutes. The chromatograms were viewed by transmitted light. The intensity of each spot was evaluated visually on an arbitrary scale ( $0-10$ units) and the degree of aminoaciduria expressed as the arithmetic sum of the spot 'values'. The ratings were made by two observers reading independently, and the average of the two totals was used. The reliability of the visual scoring method was evaluated by comparing the summed 'spot units' with a quantitative measurement of total aminoaciduria. Urine samples from nine normal children and from four patients with vitamin D deficiency were analyzed on ground ion exchange resin columns using a Beckman Spinco Model-120 amino acid analyzer [42.] A linear relation between the two methods of estimating the aminoaciduria was observed (fig. 1) in the range encountered with the majority of samples in the study.

Endogenous amino acid clearance rates were measured quantitatively using elution chromatography on ion exchange resin columns as described previously [30].

Special procedures were done on additional patients (Part II). Prolonged intravenous infusion of calcium was performed using the technique described by FrASER et al. [18]. Inorganic phosphorus was infused intra-

1 Dr. J.S.Dunbar, Radiologist-in-Chief, Montreal Ghildren's Hospital.

${ }^{2}$ SHAw, K. N.F.: personal communication. 
venously in a buffered solution as described earlier [40]. Parathyroid extract ${ }^{3}$ (PTE) was given subcutaneously in rotated sites. Blood samples in these special studies were always obtained in the fasting state in the morning to minimize the effect of diurnal and dietary variation; all serum calcium values were corrected to a standard specific gravity of 1.027 [14].

\section{Part I}

Clinical and Biochemical Correlations in the Human Vitamin D Deficiency Syndrome

The individual pretreatment values for serum calcium and phosphorus and aminoaciduria obtained from the thirty-nine patients with vitamin $\mathrm{D}$ deficiency are shown in figures $2 \mathrm{~A}$ and $2 \mathrm{~B}$. Figure $2 \mathrm{~A}$ indicates the relation of the initial calcium value to the urinary amino acid excretion; figure $2 \mathrm{~B}$ shows the relation of initial phosphorus value to urinary amino acid excretion in the same patients. The shaded area in each figure represents the normal range for aminoaciduria and for serum calcium or serum phosphorus. For purposes of discussion of the results, each graph is divided into four areas by a horizontal line, which arbitrarily differentiates normal from hypocalcemia at $9.0 \mathrm{mg} /$ $100 \mathrm{ml}$ and normal from hypophosphatemia at $4.0 \mathrm{mg} /$ $100 \mathrm{ml}$; and by a vertical line, which differentiates normal from hyperaminoaciduria at 15 units. The latter value was derived from a review of chromatograms obtained from the normal children (fig. 1).

Three groups of patients with the vitamin $\mathbf{D}$ deficiency syndrome are evident in figure 2 ; additional information on these patients is summarized in table I and as follows:

\section{Group I}

There were nine patients (solid circles, fig.2), in whom the serum calcium was less than $9.0 \mathrm{mg} / 100 \mathrm{ml}$, and in whom the serum phosphorus level was normal. Of these, six had normal aminoaciduria, and in only three was minimal hyperaminoaciduria found. In six patients, the radiological signs (solid circles, fig. 3) were confined to a loss of definition of skull sutures and some demineralization of the calvarium; this was a characteristic roentgen sign of this stage of vitamin D deficiency; in the three other patients, mild rickety changes in long bones were also seen.

Six patients presented with convulsions and one with tetany; in none was vitamin $\mathrm{D}$ deficiency the initial diagnosis. The age on admission ranged from 2-12 months, with the peak at 4-6 months.

${ }^{3}$ Para-Thor-Mone, Lilly.

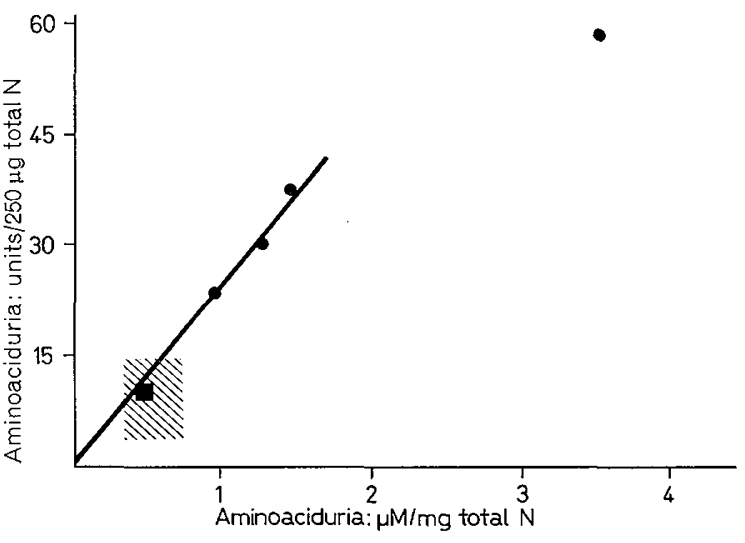

Fig. 1. Comparison of two methods of estimating aminoaciduria in nine normal infants (hatched area), and four vitamin D-deficient infants (solid circles). Quantitative values obtained by column chromatography are plotted on the abscissa; the results obtained by visual estimation of partition chromatograms (see text) are plotted on the ordinate.

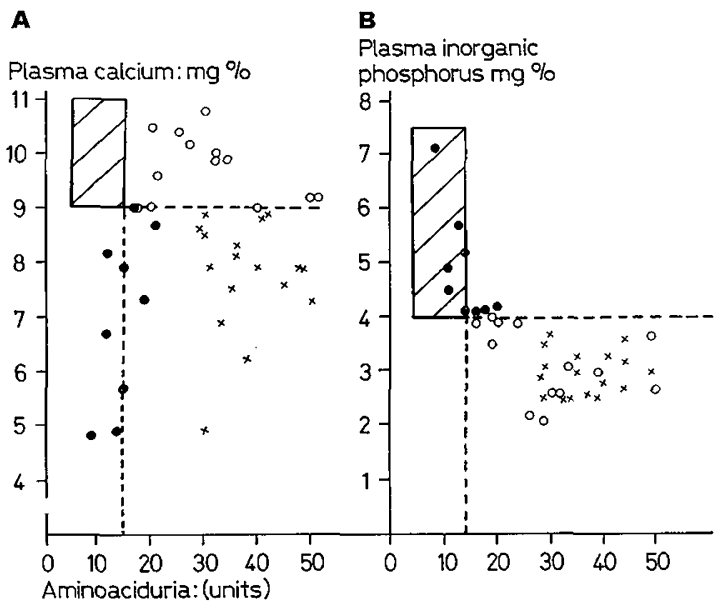

Fig. 2. A. Serum calcium values in thirty-nine vitamin D-deficient infants in relation to aminoaciduria (see text). Shaded area represents the normal range.

$B$. Serum phosphorus levels in the same patients plotted in relation to aminoaciduria. Solid circles, open circles and crosses, respectively designate early (stage I), moderate (stage II) and severe (stage III) deficiency. Shaded area represents the normal range.

\section{Group II}

There were 13 patients in this group (open circles, fig.2). In all, the serum calcium level was normal (>9.0 $\mathrm{mg} / 100 \mathrm{ml}$ ), the phosphorus level was below $4.0 \mathrm{mg} / 100 \mathrm{ml}$, and there was hyperaminoaciduria. All patients had typical radiological signs of moderate 
Table I. Data obtained from 39 infants with the vitamin D deficiency syndrome

\begin{tabular}{lllllll}
\hline $\begin{array}{l}\text { Stage of } \\
\text { deficiency }\end{array}$ & $\begin{array}{l}\text { Number of } \\
\text { patients }\end{array}$ & $\begin{array}{l}\text { Sex } \\
\mathrm{m}: \mathrm{f}\end{array}$ & $\begin{array}{l}\text { Calcium } \\
\mathrm{mg} / 100 \mathrm{ml} \\
\mathrm{mean} \pm \mathrm{SD}\end{array}$ & $\begin{array}{l}\text { Shosphorus } \\
\mathrm{mg} / 100 \mathrm{ml} \\
\mathrm{mean} \pm \mathrm{SD}\end{array}$ & $\begin{array}{l}\text { Aminoaciduria } \\
\text { units }\end{array}$ & $\begin{array}{l}\text { Alkaline } \\
\text { mhosphatase } \\
\text { K.A. units } \% \\
\text { mean and range }\end{array}$ \\
\hline I & 9 & $6: 3$ & $7.0 \pm 1.3$ & $4.9 \pm 1.2$ & $14.8 \pm 3.7$ & $71.9(35-130)$ \\
II & 13 & $9: 4$ & $9.7 \pm 0.6$ & $3.2 \pm 0.7$ & $30.0 \pm 10.9$ & $99.9(48-260)$ \\
III & 17 & $12: 6$ & $7.8 \pm 1.0$ & $3.0 \pm 0.4$ & $37.5 \pm 6.3$ & $102.4(44-220)$ \\
\hline
\end{tabular}

rickets in the long bones and costochondral junctions (open circles, fig. 3 ).

In only two patients was the diagnosis of rickets made purely on clinical signs and the history; in half of the patients, the admitting diagnosis was 'bronchopneumonia'. The age on admission ranged from 4-13 months, with a peak incidence between 6-8 months.

\section{Group III}

Seventeen patients had hypocalcemia, hypophosphatemia and hyperaminoaciduria (crosses, fig.2). Roentgen signs of rickets were florid and unmistakable in most patients (crosses, fig. 3). In four patients, roentgen signs of hpyerparathyroidism were found in long bones, phalanges or clavicles; these signs included subperiosteal erosion in phalanges and long bones and the 'rotting stump' sign in clavicles and ulna.

These infants exhibited the classical clinical signs of rickets and were diagnosed clinically. Three infants were admitted with convulsions. The age range was 4-40 months, with the peak between 6-12 months.

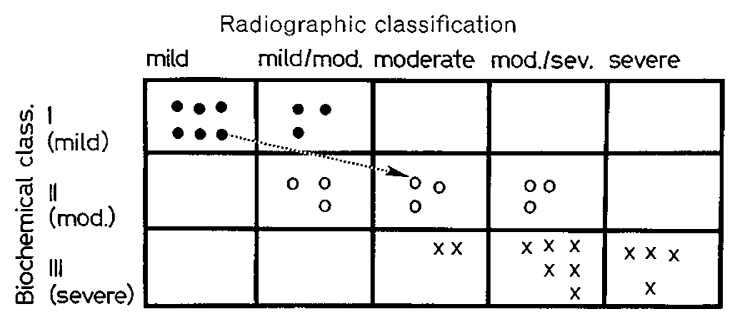

Fig.3. Roentgen signs obtained in each of thirty patients correlated with the biochemical findings from the same patient; the latter are classified according to figure 2. Criteria for the roentgen classification are: mild $=$ calvarium demineralized; mild-moderate $=$ minimal costochondral and long bone findings; moderate $=$ typical ricketic changes clearly apparent; moderate-severe $=$ advanced rickety bone changes; severe $=$ clear evidence of hyperparathyroidism in phalanges, clavicles, tibia etc. One untreated patient revealed progression of roentgen signs in a 13-day period (arrow).
Part II

Mechanism of Aminoaciduria and Phosphaturia in Human Vitamin D Deficiency

\section{Hypothesis}

The human vitamin $\mathrm{D}$ deficiency syndrome comprises three phases (Part I). This segregation can now be interpreted in terms of the new knowledge of vitamin $\mathrm{D}$ and parathyroid hormone interrelations [38]. Deficiency of vitamin $\mathrm{D}$ in the experimental animal initially impairs intestinal absorption of calcium and release of calcium from bone [2]. As a result, there is a decline in the extracellular concentration of calcium. Reactive hyperparathyroidism then occurs in response to the hypocalcemia [3]; the parathyroid response does not depend on the presence or absence of vitamin $\mathrm{D}$ itself. If sufficient vitamin $\mathrm{D}$ is still present in the tissues, parathyroid hormone can be effective in mobilizing calcium $[2,38]$; thus calcium homeostasis is repaired. In response to the accelerated synthesis and release of parathyroid hormone, there is, however, the predicted renal tubular response, with rejection of solute [2]; this renal response is not dependent on the presence or absence of vitamin $\mathrm{D}$. As the cellular depletion of vitamin $\mathrm{D}$ deficiency becomes further aggravated, maintenance of calcium homeostasis is again compromised [38], despite continuing reactive hyperparathyroidism; hypocalcemia thus may recur in severe vitamin D deficiency.

It is our contention that the hyperaminoaciduria and hypophosphatemia of human vitamin D deficiency are both directly dependent on endogenous hyperparathyroidism and not on cellular depletion of vitamin D itself. The following investigations were performed in vitamin $\mathrm{D}$-deficient infants to test this hypothesis.

\section{Results}

\section{Mechanism of the Hyperaminoaciduria}

The endogenous renal clearance rates of amino acids were measured in the fasting stage in one patient 
with stage II deficiency, and in another with stage III deficiency. The renal clearance rates of most amino acids were significantly elevated in the presence of normal plasma concentrations of the affected amino acids (table II). The hyperaminoaciduria of vitamin D deficiency is generalized and is the result of impaired tubular conservation. These data confirm the work of earlier investigators $[6,12,27]$ concerning the mechanism and composition of the hyperaminoaciduria in human vitamin $\mathrm{D}$ deficiency.

\section{Correlation of Aminoaciduria with Phosphaturia}

The hypophosphatemia of human vitamin $\mathrm{D}$ deficiency is related to its high renal clearance $[23,28]$. Inhibition of tubular absorption of phosphate, either by deficiency of vitamin $\mathrm{D}$ or by endogenous parathyroid hormone, has been proposed to account for this phenomenon $[8,21,23,43]$. If the inhibition of tubular transport of phosphate and amino acids in patients with the vitamin $\mathrm{D}$ deficiency snydrome has a common antecedent [8], then a direct relation between the excretion rates of phosphorus and amino acids might be anticipated. The inverse relation between blood phosphorus and hyperaminoaciduria, which has been observed here (fig. 2 B), and by others [8], would, in this case, also be anticipated.

A direct relation $(\mathrm{r}=0.72)$ between hyperaminoaciduria and hyperphosphaturia was observed (fig. 4) in nineteen patients with various stages of the deficiency syndrome in whom the phosphorus and amino acid content of urine was measured in the same urine sample.

Spontaneous Evolution of the Vitamin D Deficiency Syndrome Five infants with vitamin D deficiency were placed immediately at the time of diagnosis on a diet containing unenriched dairy milk; no vitamin $D$ supplement was given. Four of these patients had hypocalcemia and were classified as stage I (early) deficiency. In each patient, the serum calcium rose slowly and spontaneously (fig. 5A); this was accompanied by an increase in the aminoaciduria and a decrease in the serum phosphorus level (fig. $5 \mathrm{~B}$ ). One of these patients also exhibited progression in roentgen signs over a thirteenday period of observation (fig.3). In effect, the four patients progressed spontaneously from stage I to stage II of the deficiency syndrome.

A fifth patient (fig. 5) was initially classified as stage II deficiency on the basis of biochemical and roentgen findings. In the subsequent six days the serum calcium level fell, and the aminoaciduria increased; his serum phosphorus level remained below normal. These findings suggest a progression of the deficiency syndrome to stage III.
Table II. Endogenous renal clearance rates of amino acids in vitamin $D$ deficiency $\left(\mathrm{ml} / \mathrm{min} / 1.73 \mathrm{~m}^{2}\right)$

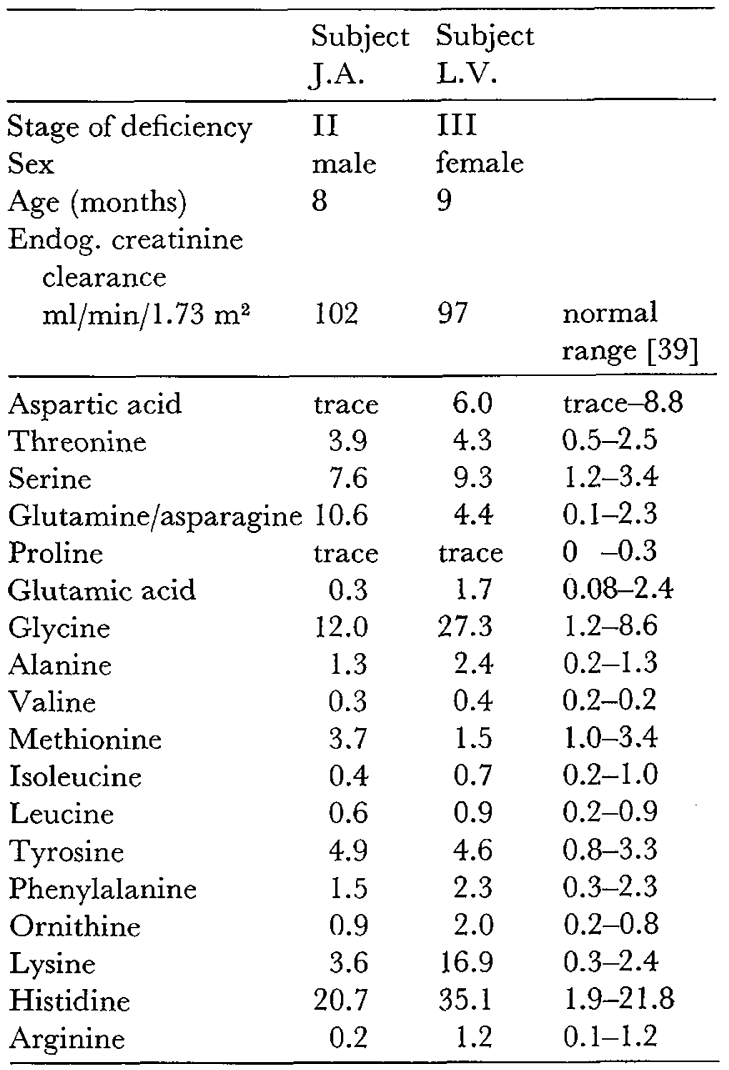

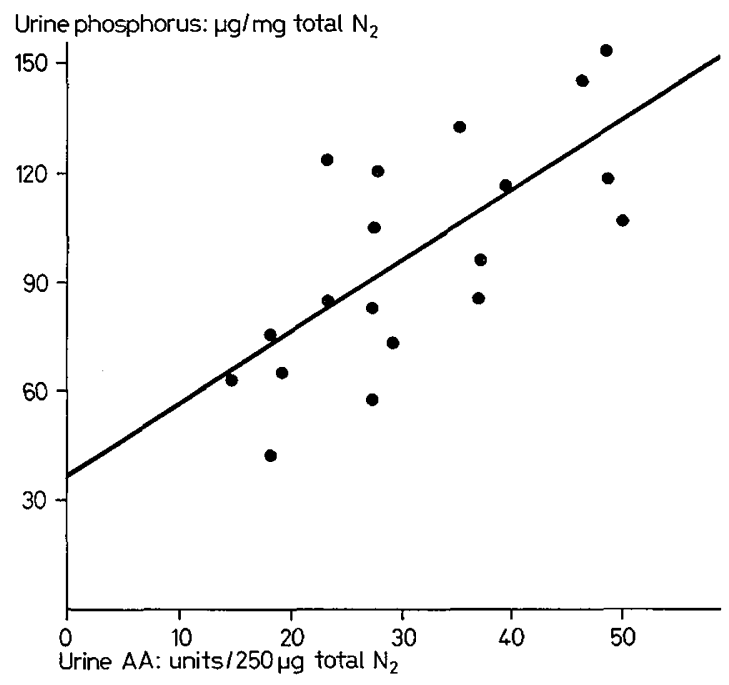

Fig. 4. Correlation of aminoaciduria and phosphaturia in nineteen patients with vitamin $\mathrm{D}$ deficiency. The correlation is significant $(r=0.72)$. Regression equation: $\mathrm{y}=36.8+1.92 \times$. 


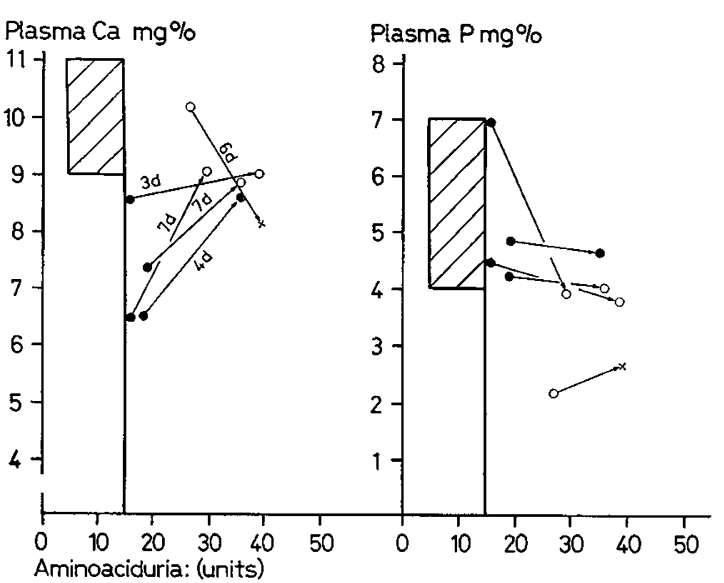

Fig.5. Changes in biochemical data in untreated patients; numerals indicate days between initial and follow-up determinations. Note progression to next stage of deficiency during elapsed time; symbols used according to classification in figure 2 and text (Part I).

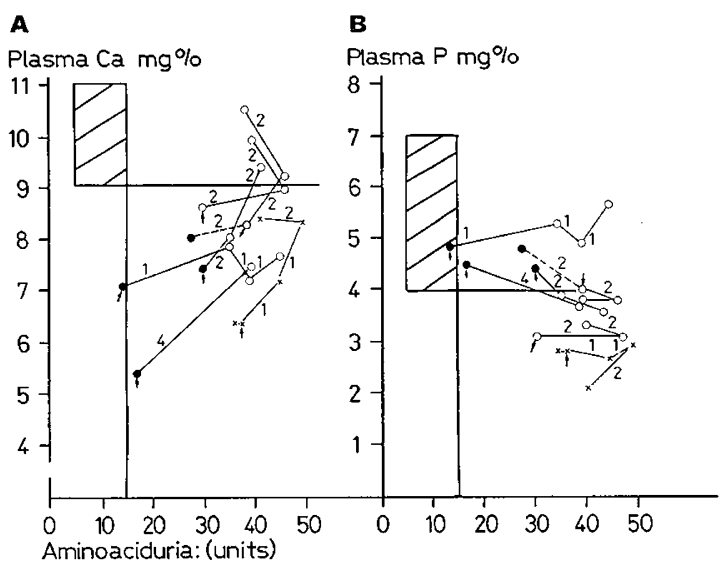

Fig.6. Response to PTE, 50 units q 6 h. Note progression from one stage of deficiency to the next. Numerals indicate days elapsed between observations. See figure 2 for symbols.
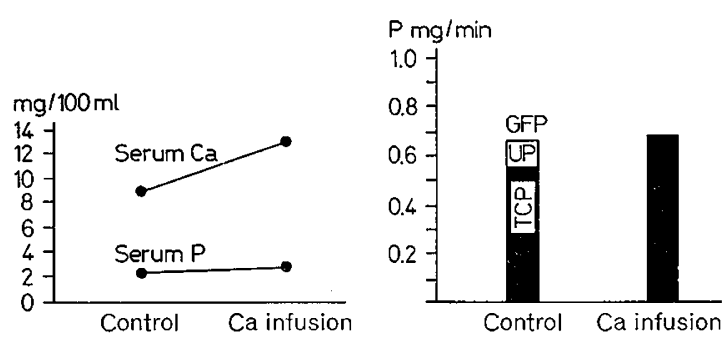

Fig.7. Tubular absorption of phosphorus in patient J.A. (table IV) in the ninth hour after hypercalcemia had been induced by intravenous calcium infusion.

\section{Response to Exogenous Parathyroid Hormone}

Parathyroid extract was given intramuscularly $(50$ USP units, $\mathrm{q} 6 \mathrm{~h} \times 4$ days) to six untreated patients (fig.6). Sufficient dosage of exogenous hormone might accelerate the transition from the existing to the next stage of the deficiency syndrome, if this transition is parathyroid dependent.

Three patients with stage I deficiency responded rapidly to PTE with increased serum calcium levels and augmented aminoaciduria; plasma phosphorus fell in two of the subjects (fig. 6). The response occurred more rapidly than in untreated patients (fig.5), suggesting that comparable changes might not have occurred during the elapsed time, in the absence of the exogenous hormone. The sequential response in time of one patient with stage $\mathrm{I}$ deficiency, before, during and after PTE, and then with vitamin $\mathrm{D}_{2}$ treatment, is presented in table III. Upon withdrawal of PTE, there is a reversion to pretreatment status.

Two patients with stage II deficiency, one of whom showed some spontaneous progression prior to injection, were also given PTE. This procedure raised the serum calcium, and aminoaciduria declined slightly during the period of calcium elevation. The existing low serum phosphorus levels did not change greatly.

In one patient with presumed stage III deficiency, the same dose of parathyroid extract used in the other patients failed to increase to serum calcium level to

Table III. Biochemical data from a patient ${ }^{1}$ with stage I deficiency before, during and after intramuscular PTE (50 units $6 q 6 h \times$ 13 doses) and then while on vitamin $D_{2}(5000$ units/day)

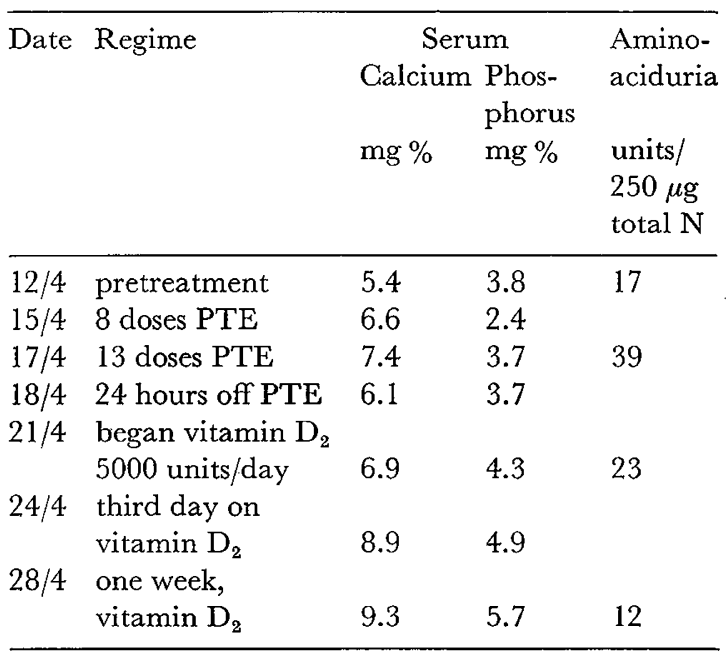

${ }^{1}$ White female infant seven months of age. Considered to be at stage $I$ of the deficiency syndrome on basis of biochemical, roentgen and clinical findings. 
Table $I V$. Amino acid reabsorption in response to calcium infusion in vitamin $\mathrm{D}$ deficiency

\begin{tabular}{|c|c|c|c|c|c|c|c|c|c|c|c|c|}
\hline \multirow{3}{*}{ Patient } & \multicolumn{4}{|c|}{$\begin{array}{l}\text { Filtered load } \\
\mu \text { moles } / \mathrm{min}\end{array}$} & \multicolumn{4}{|c|}{$\begin{array}{l}\text { Reabsorbed } \\
\% \text { of filt. load }\end{array}$} & \multicolumn{4}{|c|}{$\begin{array}{l}\text { Clearance rate } \\
\mathrm{ml} / \mathrm{min} / 1.73 \mathrm{~m}^{2}\end{array}$} \\
\hline & \multicolumn{2}{|c|}{ J.A. } & \multicolumn{2}{|c|}{ F.B. } & \multicolumn{2}{|c|}{ J.A. } & \multicolumn{2}{|c|}{ F.B. } & \multicolumn{2}{|c|}{ J.A. } & \multicolumn{2}{|c|}{ F.B. } \\
\hline & Pre & Post & Pre & Post & Pre & Post & Pre & Post & Pre & Post & Pre & Post \\
\hline Aspartic acid & 1.6 & 2.1 & 0.4 & 0.6 & 100 & 100 & 100 & 100 & 0 & 0 & $\operatorname{Tr}$ & $\operatorname{Tr}$ \\
\hline Threonine & 9.4 & 6.2 & 2.9 & 1.9 & 96.0 & 98.0 & 97.2 & 96.8 & 3.9 & 1.6 & 5.6 & 4.4 \\
\hline Serine & 12.1 & 9.4 & 5.0 & 3.0 & 92.5 & 97.0 & 96.0 & 95.4 & 7.6 & 2.5 & 8.6 & 7.2 \\
\hline \multicolumn{13}{|l|}{ Glutamine and } \\
\hline asparagine & 12.7 & 21.4 & 9.6 & 6.5 & 89.5 & 97.5 & 96.1 & 98.6 & 10.6 & 2.0 & 8.5 & 2.1 \\
\hline Proline & 12.5 & 6.8 & 6.1 & - & 100 & 100 & 100 & - & 0 & 0 & $\operatorname{Tr}$ & \\
\hline Glutamic acid & 30.9 & 9.8 & 7.9 & 5.6 & 99.5 & 100 & 99.7 & 99.8 & 0.3 & 0 & 0.6 & 2.0 \\
\hline Glycine & 14.6 & 15.5 & 6.7 & 5.2 & 88.5 & 98.0 & 87.3 & 90.7 & 12.0 & 1.8 & 26.9 & 14.0 \\
\hline Alanine & 22.4 & 14.3 & 4.9 & 7.3 & 98.5 & 99.0 & 97.5 & 98.8 & 1.3 & 0.9 & 5.1 & 1.8 \\
\hline Valine & 12.7 & 8.1 & 4.6 & 2.6 & 99.8 & 99.5 & 99.7 & 99.6 & 0.3 & 0.2 & 0.3 & 0.2 \\
\hline Methionine & 1.1 & 0.9 & 0.4 & 0.7 & 96.0 & 99.0 & 100 & 100 & 3.7 & 0.8 & $\operatorname{Tr}$ & $\operatorname{Tr}$ \\
\hline Isoleucine & 5.0 & 2.2 & 1.2 & 0.9 & 99.5 & 99.5 & 100 & 100 & 0.4 & 0.4 & $\operatorname{Tr}$ & $\operatorname{Tr}$ \\
\hline Leucine & 6.5 & 4.2 & 2.3 & 1.5 & 99.5 & 99.5 & 99.6 & 100 & 0.6 & 0.7 & $\operatorname{Tr}$ & $\operatorname{Tr}$ \\
\hline Tyrosine & 3.2 & 2.2 & 2.2 & 1.5 & 95.0 & 95.5 & 97.2 & 97.3 & 4.9 & 3.8 & 5.9 & 4.5 \\
\hline Phenylalanine & 2.6 & 2.2 & 0.9 & 1.2 & 98.0 & 97.5 & 98.8 & 97.5 & 1.5 & 1.9 & 2.9 & 3.4 \\
\hline
\end{tabular}

Serum calcium

$\mathrm{mg} / 100 \mathrm{ml} \quad 9.2 \quad 13.2 \quad 6.0 \quad 11.0$

Creatinine

clearance

$\mathrm{ml} / \mathrm{min} \quad 29.5 \quad 24.5 \quad 51.0 \quad 36.0$

the normal range; on the other hand, the hypophosphatemia was exaggerated and the aminoaciduria increased further.

\section{Response to Intravenous Calcium Infusion}

Two vitamin D-deficient patients were infused with calcium. In one patient with stage I deficiency (J.A., table IV), the infusion produced unequivocal hypercalcemia; when this had been sustained for approximately six hours, the hyperaminoaciduria began to decline. Net tubular reabsorption of amino acids had increased greatly in the seventh, eighth and ninth hours of the infusion; complete phosphate reabsorption was achieved at the same time (fig. 7). In the second patient (F.B., table IV) with stage III deficiency, the infusion achieved only a normal serum calcium level, a finding in keeping with the more severe bone changes [10]. Renal clearance of amino acids was, however, reduced by this procedure, although net tubular absorption of amino acids was less improved because of an apparent fall in glomerular filtration rate during the procedure. Calcium infusion did not appreciably alter amino acid absorption and excretion in four control patients, each affected with one variety of the Fanconi syndrome.
Note: J.A.: patient with stage II vitamin D deficiency. F.B.: patient with stage III vitamin D deficiency. Pre and Post refer to condition prior to and during the 6 th to 9 th hour of infusion.

\section{Phosphorus Infusion}

Many workers have proposed an association between phosphorus and amino acid transport $[4,8,16]$; some have suggested that the defect in phosphorus metabolism might, in itself, influence tubular absorption of amino acids [8]. One of our patients with type II deficiency was given a phosphorus infusion. The serum phosphorus level rose from 2.8 to $6.1 \mathrm{mg} / 100 \mathrm{ml}$, while the serum calcium level fell from 8.6 to $6.1 \mathrm{mg} / 100 \mathrm{ml}$. The filtered load of amino acids did not change significantly (preinfusion, $233.4 \mu$ moles $/ \mathrm{min} / 1.73 \mathrm{~m}^{2}$; infusion, $226.12 \mu$ moles $/ \mathrm{min} / 1.73 \mathrm{~m}^{2}$ ), whereas the reabsorbed fraction dropped from $94 \%$ to $87.7 \%$ during the infusion.

\section{Response to Vitamin D Therapy}

If hyperparathyroidism accounts for the aminoaciduria and phosphaturia of vitamin $\mathrm{D}$ deficiency, treatment with vitamin D should first enhance calcium homeostasis, thereby suppressing the hyperparathyroidism; then the hyperaminoaciduria and hypophosphatemia should return to normal. We followed the response to vitamin $\mathrm{D}$ therapy in patients with the deficiency syndrome (fig. 8). In two patients, serum cal- 


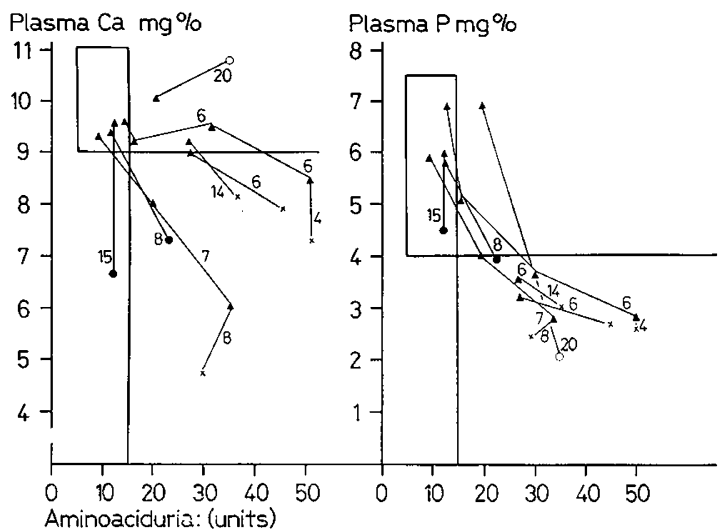

Fig. 8. Biochemical response to vitamin $\mathrm{D}_{2}$ administration (5000 units daily) in deficient infants. Numerals indicate number of days elapsed between observations. See figure 2 for symbols.

cium levels rose immediately, clearly preceding any improvement in plasma phosphorus levels and in amino acid excretion. In no patient with prior hypocalcemia did the serum phosphorus level or amino acid excretion improve without a concomitant improvement in the serum calcium level.

\section{Discussion}

Vitamin D deficiency in the human infant can be divided into three stages on the basis of the clinical data obtained in the present study (part I). We propose that endogenous hyperparathyroidism, in response to the primary effect of vitamin D deficiency upon calcium metabolism, accounts for the biochemical and clinical findings peculiar to the three stages of vitamin $\mathrm{D}$ deficiency (Part II). Although the evidence for significant hyperparathyroidism in human vitamin $\mathrm{D}$ deficiency is circumstantial $[5,10,21,23,26,28,34,43,45]$, it is quite convincing and can be summarized as follows: 1. The level of serum calcium during the three stages of deficiency (fig. 2, table I), varies in accordance with the predicted relation between PTH and vitamin D $[2,38]$ and their respective roles in the intestinal absorption of calcium and its release from bone.

2. Urinary excretion of phosphorus varies in direct proportion to the aminoaciduria in human vitamin $\mathrm{D}$ deficiency (fig. 4); plasma phosphorus levels and aminoaciduria (fig. $2 \mathrm{~B}$ ) vary inversely [8]. These phenomena consistently reflect diminished tubular absorption $[8,23]$. Parathyroid hyperactivity has been proposed on several occasions [10, 26, 34, 43, 45] to account for the hyperphosphaturia; this mechanism should also account for the aminoaciduria.
3. In human vitamin $\mathrm{D}$ deficiency, there is a natural tendency to progress in time from one stage of the biochemical syndrome to the next (fig.5). The rate of progression apparently can be accelerated by the administration of PTE (fig. 6).

4. (a) Temporary elevation of the serum calcium concentration by intravenous infusion of calcium in the face of unchanged vitamin $\mathrm{D}$ nutrition temporarily suppresses the renal tubular dysfunction (fig. 7, table IV). (b) Vitamin D therapy first enhances the restoration of normal serum calcium levels if prior hypocalcemia exists; only thereafter does any apparent tubular dysfunction subside (fig. 8).

It has been suggested that many of the biochemical and physiological features of the vitamin $\mathrm{D}$ deficiency syndrome depend on cellular depletion of the sterol itself $[8,23,28]$. However, the benefit obtained from temporary restoration of extracellular calcium levels by calcium infusion as demonstrated in this study and elsewhere [10], indicates that another mechanism for the tubular dysfunction may exist. LAVENDER and Pullman [31] have proposed that calcium ion may itself enhance tubular transport of phosphorus; they did not study the effect of this ion on amino acid absorption. However, the suppresive action of calcium upon synthesis and release of parathyroid hormone must also be considered [31, 36]. Experimental vitamin $\mathrm{D}$ deficiency in the mammal is associated with significant parathyroid hyperactivity $[2,3,11,20,32,35,37]$. Hyperplasia in explants of rat parathyroid glands and hypersecretion of calcium mobilizing hormone occur in vitro in response to diminished calcium concentration in the medium [36]. Hypertrophy and hyperfunction of parathyroid tissue also occur in vivo in the vitamin $\mathrm{D}$ deficient rat [3]; the process is dependent on the hypocalcemia and not on deficiency of vitamin $\mathrm{D}$ per se. Tubular dysfunction in the vitamin D-deficient rat can be attributed to a direct effect of parathyroid hormone $[2,20]$; the abnormality in the rat is not dependent on cellular depletion of vitamin D itself, and it is enhanced by exogenous PTE and suppressed by calcium infusion or parathyroidectomy [20].

One may thus believe by analogy that the tubular dysfunction of vitamin $\mathrm{D}$ deficiency in man is indeed parathyroid dependent; however, there are noteworthy differences between the species in their response to vitamin $\mathrm{D}$ deficiency. For instance, the rat, unlike the human and the dog, does not develop marked hypophosphatemia in advanced vitamin $\mathrm{D}$ deficiency, which may explain the relative rarity of rickets in the rat exposed to simple vitamin $\mathrm{D}$ deficiency [22]. The tubular response also varies in different species; aminoaciduria appears relatively early (stage II) in the human deficiency syndrome, but only after severe hypocalcemia has been present for several weeks in the rat 
[33], and it apparently never occurs in the hypocalcemic, vitamin D-deficient dog ${ }^{4}$.

The hypothesis could be strengthened if primary hyperparathyroidism in man were known to be accompanied by high renal clearance of amino acids and phosphorus. Documentation of hormone-dependent hyperaminoaciduria is rare in reports on primary hyperparathyroidism $[24,29]$; others have stated it to be absent [28]. However, a review of the data on 127 patients with primary hyperparathyroidism from the series of DENT [15] revealed that some degree of renal hyperaminoaciduria is present in $44 \%$ of the total group; the incidence is higher $(65 \%)$ in those first presenting with bone disease. The hyperaminoaciduria (and hyperphosphaturia) disappears after corrective surgical parathyroidectomy in most patients.

A number of interesting clinical features of the human vitamin $\mathrm{D}$ deficiency syndrome merit attention. In the present study, a sex ratio of $2: 1$ in favor of affected males was observed in vitamin $\mathrm{D}$ deficiency (table I). A similar ratio has also been reported by others [7, 33]. The significance of this finding is not clear; there is, of course, at least one X-linked gene which is responsible for renal tubular conservation of phosphorus [49], but how this predisposes to the manifestation of vitamin $\mathrm{D}$ deficiency in males is unknown.

In severe vitamin $\mathrm{D}$ deficiency, PTE may be relatively ineffective in raising the serum calcium level; this was observed in the present study (fig.6) and also by earlier investigators $[28,45]$. The 'pseudohypoparathyroidism' proposed to explain this observation [45] can be reinterpreted as the requirement for vitamin $D$ to mediate the action of PTH on intestinal absorption of calcium and on release of calcium from bone [23, 38]. Severe deficiency of the vitamin blocks the homeostatic effect of PTH; hence the fall in blood calcium levels and the poor response to PTE in raising serum calcium levels [2]. On the other hand, the tubular response to PTE does not require vitamin $\mathrm{D}[2,20]$; hyperaminoaciduria and the anticipated effects on phosphorus metabolism are thus observed following PTE injection in the deficient human infant (fig.6).

The initial stage of the deficiency syndrome is important because of the clinical predilection for tetany or convulsions; its sole biochemical manifestation is hypocalcemia. Roentgen findings are minimal and effectively limited to the skull. Unless this stage of the syndrome, which is found in young infants in the early months of the year, is recognized, the infant will remain at risk until the second stage of deficiency evolves, or until the infant receives vitamin $\mathrm{D}$. One of the most intriguing questions about the human deficiency syn-

${ }^{4}$ Fraser, D.; Kooh, S.W. and Paunier, L.: unpublished data. drome concerns the existence at any time of stage $\mathbf{I}$ deficiency. Why does hypocalcemia appear and then persist for several days; why is there no immediate effective parathyroid response at this time?

\section{References and Notes}

1. Albright, F.W. and Reifenstern, E.C.: The parathyroid glands and metabolic bone disease: Selected studies (Williams and Wilkins, Baltimore 1948).

2. Arnaud, G. ; Rasmussen, H. and Anast, G.: Further studies on the interrelationship between parathyroid hormone and vitamin D. J. clin. Invest. 45: 1955 (1966).

3. Av, W.Y.W. and RArsz, L. G.: Effect of vitamin D and dietary calcium on parathyroid activity. Amer.J. Physiol. 209: 637 (1965).

4. Ayer, J. L.; Schuess, W.A. and Pitts, R. F.: Independence of phosphate reabsorption and glomerular filtration in the dog. Amer.J. Physiol. 151: 168 (1947).

5. BALl, J.: Disease of bone: Osteomalacia; in: Recent advances in pathology (ed. HARRISON, G.V.), 7th ed., pp. 314-338 (J. and A. Churchill, London 1960).

6. Berger, H. und Stalder, G.: Zur Frage der Aminoacidurie bei der Vitamin-D-Mangelrachitis der Säuglinge. Ann. Paediat. (Basel) 186: 163 (1956).

7. Gillds, B.; Cantolino, S. and Dyke, M. K.: Observations on sex differences in human biology. Bull.Johns Hopk. Hosp. 110: 134 (1962).

8. Chisholm, J.J., Jr. and Harrison, H.E.: Aminoaciduria in vitamin $\mathrm{D}$ deficiency states in premature infants and older infants with rickets. J. Pediat. 60: 216 (1962)

9. Clark, E.P. and Collip, J.B.: A study of the Tisdall method for the determination of blood serum calcium with a suggested modification. J. biol. Chem. 63: 461 (1925).

10. Cossimos, C.; Tsenghi, C.; Mrahael, S.; Liaromati, A. and Metaxotou, K.: Continuous intravenous infusion of calcium in vitamin $\mathrm{D}$ deficient rickets. Pediatrics 31: 272 (1963).

11. Grawford, J.D.; Gribetz, D.; Diner, W. G.; Hurst, P. and Castleman, B.: The influence of vitamin $\mathrm{D}$ on parathyroid activity and the metabolism of calcium and citrate during calcium deprivation. Endocrinology 61: 59 (1957).

12. Cusworth, D.C. and Dent, C.E.: Renal clearances of amino acids in normal adults and in patients with aminoaciduria. Biochem.J. 74: 550 (1960). 
13. Dent, C. E. : A study of the behaviour of some sixty amino acids and other ninhydrin reacting substances on phenol-'collidine'filter paper chroma tograms with notes as to the occurrence of some of them in biological fluids. Biochem.J. 43: 169 (1948).

14. Dent, C.E.: Some problems of hyperparathyroidism. Brit.med.J. ii: 1419 (1962).

15. Dent, G. E. and Cusworth, D.: Personal communication (1965).

16. Drummond, K.N. and Mrahael, A.F.: Specificity of the inhibition of tubular phosphate reabsorption by certain amino acids. Nature (Lond.) 201: 1333 (1964).

17. Fiske, C.H. and Subbarrow, Y.: The colorimetric determination of phosphorus. J. biol. Ghem. 66: 375 (1925).

18. Fraser, D.; Leeming, J. M. und Cerwenka, E.A.: Über die Handhabung von Phosphat durch die Nieren bei hypophosphatämischer Vitamin-Dresistenter Rachitis der einfachen Art und bei Cystinspeicherkrankheit. Reaktion auf verlängerte Calciuminfusion. Helv. Paediat. Acta 14: 497 (1959).

19. Freudenberg, E. und Goetz, H.: Die Stoffwechselwirkung des D-Vitamin-Stoßes bei Rachitis und Tetanie. Ann. paediat. (Basel) 153: 233 (1939).

20. Grose, J. and Scriver, C.R.: Parathyroid dependent phosphaturia and aminoaciduria in the vitamin $\mathrm{D}$ deficient rat. Amer. J. Physiol. (in press).

21. Ham, A.W.; Litrner, N.; Drake, G.H.; Robertson, E. C. and Tisdall, F.F.: Physiological hypertrophy of parathyroids, its cause and its relation to rickets. Amer.J. Path. 16: 277 (1940).

22. Harrison, H. C.; Harrison, H. E. and PARk, E.A.: Vitamin D and citrate metabolism: Effect of vitamin $\mathrm{D}$ in rats fed diets adequate in both calcium and phosphorus. Amer.J. Physiol. 192: 432 (1958).

23. Harrison, H.E.: Vitamin D and calcium in phosphate transport. Pediatrics 28: 531 (1961).

24. Hillman, D.A.; Scriver, C.R.; Pedvis, S. and SHRAGovitch, I.: Neonatal familial primary hyperparathyroidism. New Engl.J.Med. 270: 483 (1964).

25. Hottinger, A. und Hottinger, G.: Studien über Säure-Basen-Haushalt im kindlichen Organismus. II. Mitteilung. Mschr. Kinderheilk. 52: 204 (1932).

26. Illig, R.; Uehlinger, E. und Prader, A.: Sekundärer Hyperparathyroidismus bei Vitamin-DMangel-Rachitis. Helv.paediat. Acta 14: 566 (1959).

27. Jonxis, J.H.P.: Aminoaciduria and rickets. Helv. paediat. Acta 10: 245 (1955).

28. Jonxis, J.H.P.: Phosphate metabolism in rickets and tetany. Helv. paediat. Acta 14: 491 (1959).
29. Khachadurian, A. K.: Amino-aciduria secondary to a functioning parathyroid carcinoma. Ann.intern. Med. 56: 931 (1962).

30. KING, E. J. : Microanalysis in medical biochemistry, 3rd ed. (J. and A. Churchill, London 1959).

31. Lavender, A.R. and Pullman, T.N.: Changes in inorganic phosphate excretion induced by renal arterial infusion of calcium. Amer. J. Physiol. 205: 1025 (1963).

32. Leeming, J. M. and Fraser, D.: Dependence upon intact parathyroids for action of vitamin $D$ on renal phosphate conservation in the rachitic puppy. J. Pediat. 63: 729 (1963).

33. Lelong, M.; Canlorbe, P.; Paupe, J.; Colln, J.; Gentil, G. et Hennemanne, G.: Circonstances d'apparition du rachitisme commun. Ann. Pédiat. 37: 547 (1961).

34. Lelong, M.; Colin, J.; Paupe, J.; Gentil, C.; Canlorbe, P. et Hennemanne, G.: Calcium et phosphore plasmatiques et urinaires au cours du rachitisme commun. I: Avant traitement. Ann. Pédiat. 37: 529 (1961).

35. Ney, R.L.; Au, W.Y.W.; Kelly, G.; Radde, I. and BArtter, F. G.: Actions of parathyroid hormone in the vitamin D-deficient dog. J. clin. Invest. 44: 2003 (1965).

36. Raisz, L.G.; Aug, W.Y.W. and Stern, P.H.: Regulation of parathyroid activity; in: The Parathyroid Glands: Ultrastructure, secretion and function (ed. Gaillard, P.J.; Talmage, R.V. and Budy, A.M.), pp.37-53 (University of Chicago Press, Chicago 1965).

37. Rasmussen, H.; Deluca, H.; Arnaud, C. ; Hawker, C. and von Stedingk, M. : The relationship between vitamin $\mathrm{D}$ and parathyroid hormone. J. clin. Invest. 42: 1940 (1963).

38. Rasmussen, H. und DeLuca, H.F.: Calcium Homeostasis. Ergebn. Physiol. exp. Pharmakol. 53: 108 (1963).

39. Sariver, C.R. and Davies, E.: Endogenous renal clearance rates of free amino acids in pre-pubertal children. Pediatrics 36: 592 (1965).

40. Sariver, G. R.; Goldbloom, R.B. and Roy, C.C.: Hypophosphatemic rickets with renal hyperglycinuria, renal glucosuria, and glycylprolinuria. A syndrome with evidence for renal tubular secretion of phosphorus. Pediatrics 34: 357 (1964).

41. Sariver, G.R.; КоOH, S.W. and Fraser, D.: Aminoaciduria in vitamin $\mathrm{D}$ deficiency rickets and in disturbances of parathyroid function. J. Pediat. 66: 1085 (1964).

42. Spackman, D.H.; Stein, W.H. and Moore, S.: Automatic recording apparatus for use in the chromatography of amino acids. Anal. Chem. 30: 1190 (1958). 
43. Stanbury, S.W.: Some aspects of disordered renal tubular function. Advanc.intern. Med. 9: 231 (1958).

44. Stowers, J. M. and Dent, G. E. : Studies on mechanism of Fanconi syndrome. Quart.J. Med. 16: 275 (1947).

45. TArtz, L.S. and deLacy, C. D.: Parathyroid function in vitamin $D$ deficiency rickets. II. The relationship of parathyroid function to bone changes and incidence of tetany in vitamin $\mathrm{D}$ deficiency rickets in South African Bantu infants. Pediatrics 30: 884 (1962).

46. VISAKORPI, J.K.: Aminoaciduria in various types of rickets. Ann. Paediat. Fenn. 6: Suppl. 16: 7 (1960).

47. Whitten, G.F.: The defect in renal acidification in vitamin $\mathrm{D}$ deficiency rickets. J.Pediat. 69: 80 (1966).

48. WinberG, J. and Bergström, T.: Renal acidification defect in infants with mild deficiency rickets. Acta paediat. (Uppsala) 54: 139 (1965).

49. Winters, R.W.; Graham, J.B.; Williams, T.F.; MaFalls, V.W. and Burnett, C.H.: A genetic study of familial hypophosphatemia and vitamin D resistant rickets with a review of the literature. Medicine (Baltimore) 37: 97 (1958).

50. The authors express their appreciation for the technical assistance of Miss Dorothy Cameron, Mrs. Garol Glow and Miss Eluned Davies of the McGill University-Montreal Children's Hospital Research Institute, the technical assistance of Mrs. I. UNTERBERGER and the advice of Dr. LUC PAUNIER of the Research Institute of The Hospital for Sick Children.

51. This investigation was supported by grants, MT1085 from the Medical Research Council of Canada, and AM-05117 from the National Institutes of Health (U.S.A.) to C.R.S.; and by grants MT1583 and MA-2131 from the Medical Research Council of Canada, and 605-13-69 from the Department of National Health to D.F.

52. Presented in part at the Society for Pediatric Research, Seattle, Washington, 1964 [41].

53. Sariver, C.R., M.D., The McGill UniversityMontreal Children's Hospital Research Institute, 2300 Tupper Street, Montreal 25, Quebec (Canada). 